This is the accepted manuscript made available via CHORUS. The article has been published as:

\title{
Phase behavior and characterization of heptamethyltrisiloxane-based de Vries smectic liquid crystal by electro-optics, $x$ rays, and dielectric spectroscopy
}

S. P. Sreenilayam, D. M. Agra-Kooijman, V. P. Panov, V. Swaminathan, J. K. Vij, Yu. P. Panarin, A. Kocot, A. Panov, D. Rodriguez-Lojo, P. J. Stevenson, Michael R. Fisch, and Satyendra Kumar

Phys. Rev. E 95, 032701 - Published 10 March 2017 DOI: 10.1103/PhysRevE.95.032701 
1 The Phase behaviour and the characterization of heptamethyltrisiloxane

2 based de-Vries SmA* liquid crystal by electro-optics, $\mathrm{x}$-rays and

3 dielectric spectroscopy

4

S. P. Sreenilayam ${ }^{\mathrm{a}}$, D. M. Agra-Kooijman ${ }^{\mathrm{b} \dagger}$, V. P. Panov ${ }^{\mathrm{a}}$, V. Swaminathan ${ }^{\mathrm{a}}$, J. K. Vij ${ }^{\mathrm{a}}$, Yu. P.

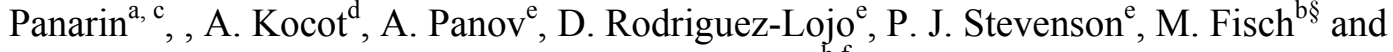
Satyendra Kumar,

${ }^{\mathrm{a}}$ Department of Electronic and Electrical Engineering, Trinity College,-The University of Dublin, Dublin 2, Ireland

${ }^{\mathrm{b} \dagger}$ Department of Physics and ${ }^{\S}$ College of Applied Engineering Sustainability and Technology Kent State University, Kent, OH 44242

${ }^{\mathrm{c}}$ School of Electrical and Electronic Engineering, Dublin Institute of Technology, Dublin 8, Ireland

${ }^{\mathrm{d}}$ Institute of Physics, Silesian University, Katowice, Poland

${ }^{\text {e}}$ School of Chemistry and Chemical Engineering, Queens University, Belfast, BT7 1NN, U. K.

${ }^{\mathrm{f}}$ Division of Research and Department of Physics, University at Albany, Albany, NY 12222

A heptamethyltrisiloxane liquid crystal (LC) exhibiting Iso-SmA*-SmC* phases has been characterized by calorimetry, polarizing microscopy, x-ray diffraction, electro-optics and dielectric spectroscopy. Observations of a large electro-clinic effect, a large increase in the birefringence $(\Delta n)$ with electric field, a low shrinkage in the layer thickness $(\sim 1.75 \%)$ at $20{ }^{\circ} \mathrm{C}$ below the $\mathrm{SmA}^{*}$ to $\mathrm{SmC}^{*}$ transition, and low values of the reduction factor ( $\sim 0.40)$ suggest that $\mathrm{SmA}^{*}$ phase in this material is of the de-Vries type. The reduction factor is a measure of the layer shrinkage in $\mathrm{SmC}^{*}$ phase and it should be zero for an ideal de-Vries. Moreover, a decrease in the magnitude of $\Delta n$ with decreasing temperature indicates the presence of the temperature-dependent tilt angle in the $\mathrm{SmA}$ * phase. The electro-optic behavior is explained by the generalized Langevin-Debye model as given by Shen et al. [Phys. Rev. E 88, 062504 (2013)]. The soft mode dielectric relaxation strength shows a critical behavior when the system goes from $\mathrm{SmA}^{*}$ to $\mathrm{SmC}^{*}$ phase.

*Corresponding Author: jvij@.tcd.ie 


\section{INTRODUCTION}

In liquid crystalline (LC) compounds, the phase transition from the orthogonal (SmA) to tilted $(\mathrm{SmC})$ smectic phases is associated with an appearance of tilt $(\theta)$ between the molecular long axis $\boldsymbol{n}$ and layer normal $\boldsymbol{z}$ (Fig. 1a) Due to this tilt, the layer spacing in the SmC phase $\left(d_{C}\right)$ is smaller than in SmA $\left(d_{A}\right)$. In the realm of the rigid-rod molecular model being valid (Fig. 1a), the smectic layer thickness $d_{C}$ is reduced from $d_{A}$ by $\cos \theta$ [1-3]. In conventional SmC LCs, $\theta$ varies from zero to $\sim 30^{\circ}$ depending on temperature. The large layer contraction in ferroelectric SmC* induces chevron structures which in turn results into zigzag defects [4]. These defects present a roadblock to a successful commercialization of the ferroelectric LC (FLC) devices. The FLC devices intrinsically have faster switching modes [5] than their nematic counterparts that are currently predominantly used in the industry. The objective is therefore to eliminate these zigzag defects by making the smectic layer thickness almost independent of temperature so as to have the most desirable features of FLCs in the next generation of displays.

In 1972, Diele et al. reported a non-chiral LC with the same layer spacing in the SmC and SmA [6]. To explain it, de-Vries proposed a new type of SmA phase where the molecules are tilted as in $\mathrm{SmC}$ with two possible structures. In one case [7,8], SmC-like layers are stacked in a random fashion. In other words tilt directions with the same tilt angle in different layers are randomly oriented. This implies that the azimuthal angle $(\varphi)$ varies randomly from on layer to next: no long range correlations in the azimuthal angle of the smectic layers was proposed to exist in this case. In the second model of de-Vries [9], the molecules are tilted and the correlation in the tilt direction exists within a single layer too, i.e. $\varphi$ has a finite-correlation length. If the correlation length is much smaller than wavelength of the visible light, then the phase in optical experiments should behave as 'a uniaxial SmA'. The results of both de-Vries models should be that the directors in SmA phase would be distributed on to a cone as shown in Fig. 1b.

The chiral de-Vries materials show electro-optic behavior due to the field-induced azimuthal reorientation of the molecules on the cone and the apparent tilt angle measured by an optical experiment in SmA thus increases with the field. They exhibit a significantly large electroclinic effect due to the azimuthal reorientation and the induced tilt becomes saturated at "high" electric fields once the degeneracy in the azimuthal angle is lost (the azimuthal angle is condensed to values within narrow limits). For the zero external field, the maximum of the molecular orientational distribution function is at the cone angle (volcano distribution) rather than at the layer normal. The de-Vries behavior can be described by the reduction factor defined 
71 as, $R=\frac{\delta(T)}{\theta_{\text {opt }(T)}}=\cos ^{-1}\left[d_{C}(T) / d_{A C}\right] / \theta_{\text {opt }}(T)$; where $\delta(T)$ is the tilt angle for the layer shrinkage 72 relative to layer thickness $d_{A C}$ at the smectic A-C transition and $\theta_{\text {opt }}$ is the optical tilt angle 73 determined by the polarizing optical microscopy [10, 11]. An ideal de-Vries material producing 74 defect-free bookshelf geometry in $\mathrm{SmC}^{*}$ phase will have the reduction factor $R=0$.

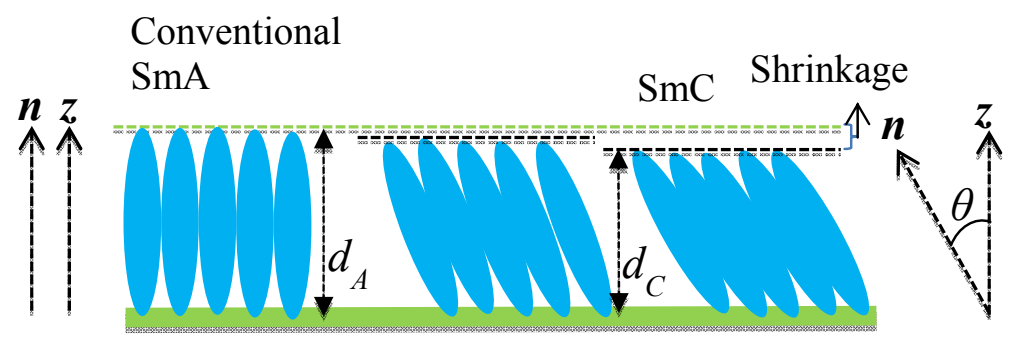

(a)

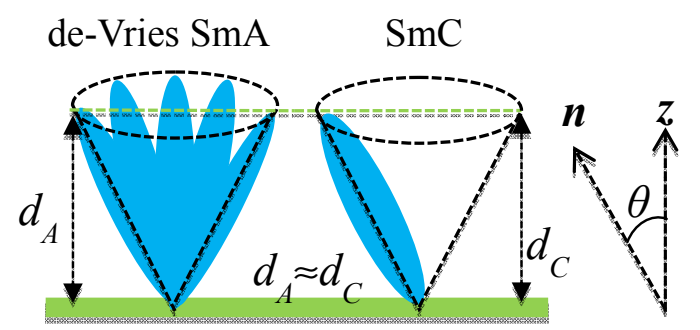

(b)

75

76

77

78

79

80

81

82

83

84

85

86

87

FIG. 1: Schematic representation of (a) conventional SmA-SmC (rigid rod model) and (b) de-Vries SmA-SmC (diffuse cone model) phase transition. Here, $\boldsymbol{z}$ is the layer normal, $\boldsymbol{n}$ is the molecular long axis orientation, $\theta$ is the angle between $\boldsymbol{n}$ and $\boldsymbol{z}, d_{C}$ and $d_{A}$ are the layer spacings in SmC and SmA phases, respectively.

Several research groups reported de-Vries type behavior in smectic LCs composed of non-chiral [12-14] and chiral [15-19] molecules. LC materials that behave as 'good de-Vries like' so far are siloxane-terminated TSiKN65 compound [20], its carbosilane-terminated analogue W599 [21] and the 2-phenylpyrimidine derivative 8422[2F3] [22]. For these materials, the layer contraction at the smectic $\mathrm{A}^{*} \mathrm{C}^{*}$ transition lies in the range of 0.65 to $1 \%$. In this paper, we present experimental results on the calorimetric, optical, polarization measurements, dielectric spectroscopy and x-ray diffraction on heptamethyl- trisiloxane derivative $\mathrm{MSi}_{3} \mathrm{MR} 11$, which exhibits a strong electroclinic effect with birefringence strongly increasing at SmA* $\mathrm{SmC}^{*}$ phase transition. Experimental results suggest that the $\mathrm{SmA}^{*}$ phase in this material is of de-Vries type. The reduction factor for this material is found to be $\sim 0.40$. The electro-optic response and the induced polarization are found to be in agreement with the generalized Langevin-Debye model. The soft mode relaxation strength of de-Vries type SmA* phase as a function of temperature exhibits critical nature when the system undergoes a transition to SmC* phase. 


\section{EXPERIMENTAL}

The molecular structure and the transition temperatures of the $\mathrm{MSi}_{3} \mathrm{MR} 11$ are shown in

Fig. 2a. This compound was resynthesized and it has two chiral centres. The synthetic procedure is given in the appendix A. One of the objectives here is to see whether two chiral centres give rise to a similar phenomenon as compounds with one chiral centre. The mesogenic core of MR11 consists of a biphenyl 2-chloro-3-methylpentanoate unit. Here 'M (mono-substituted)'stands for the number of siloxane end groups attached to the mesogen MR11. The mesogen MR11 [23] with 11 methylene units is attached to a trisiloxane backbone. The purity of the sample was found to much higher through its analysis by NMR than for the previously synthesized sample [23]. An analysis for the purity of the sample is given in the appendix A. The transition temperatures (Fig. 2a) are obtained on cooling under quasi-equilibrium condition with a cooling rate of $\sim 1^{\circ} \mathrm{C} \min ^{-1}$ using polarizing microscopy.

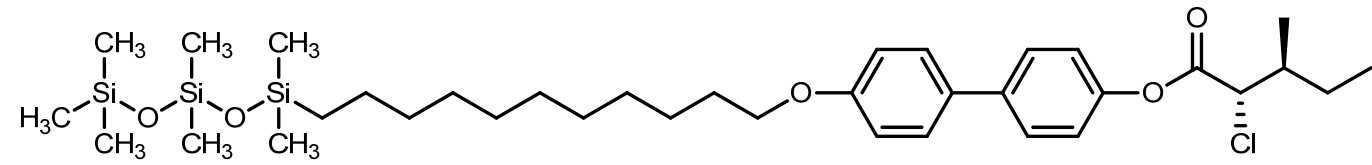

(a)

\section{$\mathrm{Cr} \mathbf{1 6}^{\circ} \mathrm{C}[-5.12 \mathrm{~J} / \mathrm{g}] \mathrm{SmC} * \mathbf{4 7}^{\circ} \mathrm{C}[-1.06 \mathrm{~J} / \mathrm{g}] \mathrm{SmA} * \mathbf{5 9}^{\circ} \mathrm{C}[-5.56 \mathrm{~J} / \mathrm{g}]$ Iso}

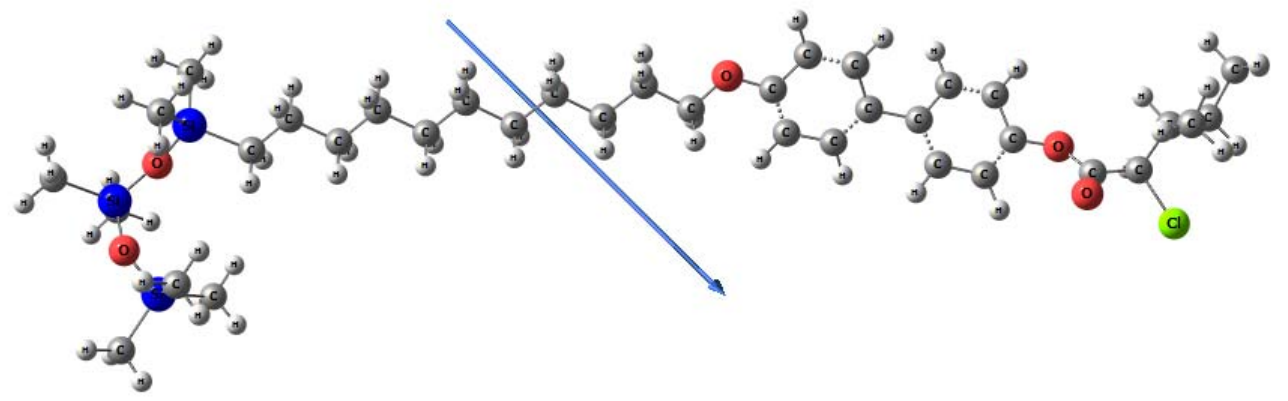

(b)

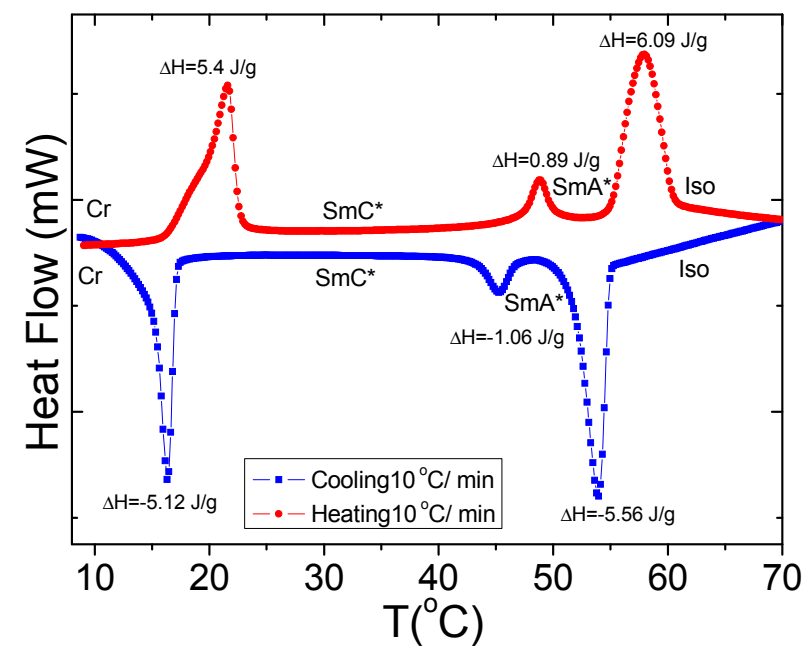

(c) 
FIG. 2 (color online) (a) Molecular structure of the LC material $\mathrm{MSi}_{3} \mathrm{MR} 11$, phase sequences and the transition temperatures $\left({ }^{\circ} \mathrm{C}\right)$ with enthalpies $(\mathrm{J} / \mathrm{g}$, in square brackets). (b) Optimized molecular geometry of $\mathrm{MSi}_{3} \mathrm{MR} 11$. The arrow in Fig. $1 \mathrm{~b}$ shows the direction of the molecular dipole moment (3.562 D).(c) DSC cooling and heating curves obtained at the rate of $10{ }^{\circ} \mathrm{C} \mathrm{min}^{-1}$. The transition temperatures are obtained from the cooling cycle under the quasi-equilibrium condition at a rate of $\sim 1$ ${ }^{\circ} \mathrm{C} \min ^{-1}$ using polarizing microscopy. Iso=isotropic state, $\mathrm{Cr}=$ crystalline state.

The optimized geometry of $\mathrm{MSi}_{3} \mathrm{MR} 11$ (shown in Fig. 2b) is obtained by Density Functional Theory (DFT) using B3LYP method with a 6-31G (d,p) level basis set. Optimized geometry computations were carried out using Gaussian 09 software package [24]. The DSC thermograms obtained for $\mathrm{MSi}_{3} \mathrm{MR} 11$ are shown in Fig. 2c. In both heating and cooling cycles, this material exhibits three transition peaks. The peaks in the DSC correspond to the phase transitions I - SmA*, SmA* - SmC* and the crystalline state. These phases are additionally characterized by polarizing optical microscopy. During the cooling cycle, enthalpy of the phase transition Iso-SmA* is $-5.56 \mathrm{~J} / \mathrm{g}$, whereas that of $\mathrm{SmA}^{*}-\mathrm{SmC}^{*}$ is $-1.06 \mathrm{~J} / \mathrm{g}$. The enthalpies associated with the transition temperatures (first cooling and second heating rates of $10{ }^{\circ} \mathrm{C} \min ^{-1}$ ) show that the $\mathrm{SmA}^{*}-\mathrm{SmC}^{*}$ phase transition is weakly of the first order $[8,25]$.

The representative optical textures in the $\mathrm{SmA}^{*}$ and $\mathrm{SmC}^{*}$ phases (Fig. 3) were recorded using the polarizing optical microscope (Olympus BX51) equipped with a CCD camera (SPOT, Diagnostic Instruments, Inc.) on a non-oriented sample prepared between a glass slide and cover slip placed in a Mettler Hotstage (FP82HT) with a thermal stability of $\pm 0.1^{\circ} \mathrm{C}$.

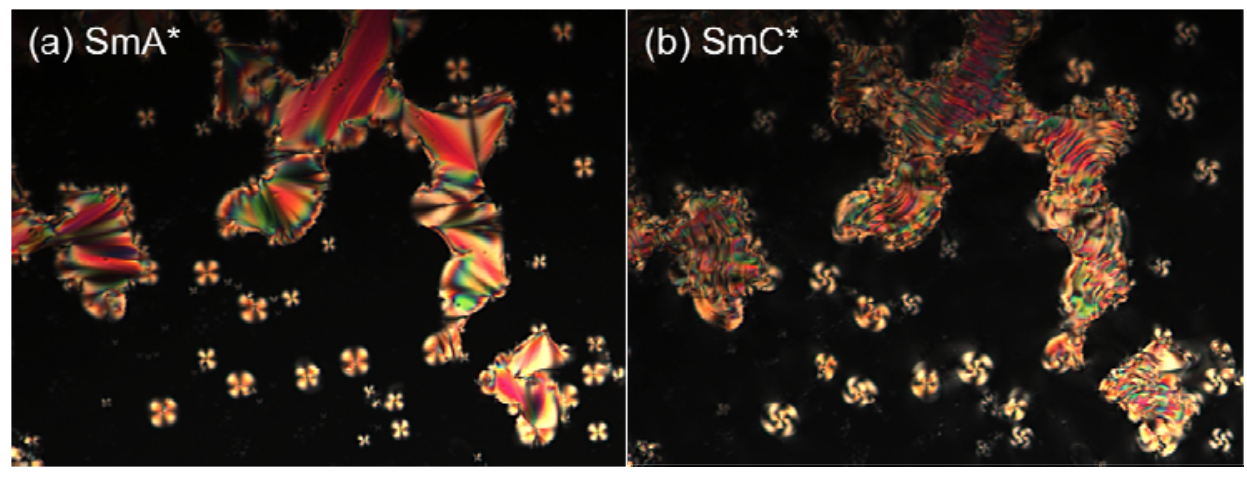

FIG. 3 (color online) Optical textures of MSi3MR11 in (a) SmA*, $5{ }^{\circ} \mathrm{C}$ above the SmA-SmC* transition, $\mathrm{T}_{\mathrm{AC}}$, and (b) $\mathrm{SmC}^{*}\left(0.4{ }^{\circ} \mathrm{C}\right.$ below $\left.\mathrm{T}_{\mathrm{AC}}\right)$, phases. The dark regions in the texture correspond to homeotropically aligned LC molecules.

The x-ray diffraction was studied on a sample contained in a flame sealed $1.0 \mathrm{~mm}$ quartz capillary and placed inside a Linkam hotstage (HFSX350-CAP) with $0.05{ }^{\circ} \mathrm{C}$ precision 
142 temperature controller (T95-HS) for a definitive identification of the smectic phases and for

143 temperature dependence studies of the structure parameters such as the layer spacing, tilt angle

144 and the orientational order parameters. The x-ray diffraction measurements were performed 145 using a microfocus Rigaku Screen Machine (Copper anode, $\lambda=1.542 \AA$ ) and the diffraction

146 patterns recorded by Mercury 3 CCD detector of resolution $1024 \times 1024$ pixels (size: $73.2 \times 73.2$

$147 \mu \mathrm{m}^{2}$ ) placed $\sim 73 \mathrm{~mm}$ from the sample. The data was calibrated against silver behenate standards

148 traceable to the National Institute of Standards and Technology. Data analyses were carried out

149 using FIT2D software [26] and Mathematica on the background corrected data (i.e. scattering

150 from an empty capillary was subtracted from the measured scattering data).

151 Electro-optic studies were made on planar cells filled with the material under study. The 152 planar alignment in this cell is achieved by coating the indium tin oxide glass substrates with a 153 RN1175 polymer alignment layer (Nissan Chemicals Japan) and baking the substrates at a 154 temperature of $250{ }^{\circ} \mathrm{C}$ for 30 minutes. The gap between the substrates is controlled by Mylar 155 spacers and the actual cell thickness is measured by the technique based on the optical 156 interference of reflected beams of light from the inner faces of the substrates of the cell. The 157 phases are characterized by using a polarizing optical microscope (Olympus BX 52) fitted with a 158 hot stage connected to a temperature controller (Eurotherm 2604). The electro-optic behavior of 159 the different phases is investigated by applying AC voltages of different amplitudes from a 160 signal generator (Agilent 33120A) amplified by a high voltage amplifier (TReK PZD700). 161 Dielectric spectroscopy over a frequency varying from $1 \mathrm{~Hz}-10 \mathrm{MHz}$ is carried out using a 162 broadband Alpha High Resolution Dielectric Analyzer (Novocontrol GmbH, Germany) under 163 the application of a weak electric field of $\left(0.1 \mathrm{~V}_{\mathrm{rms}}\right)$ applied across the cell with brass 164 electrodes.Temperature of the LC sample filled in the cell of gold coated brass electrodes is 165 stabilized to $\pm 0.05{ }^{\circ} \mathrm{C}$. The dielectric spectra are recorded during the cooling process from the 166 isotropic state.

\section{3. RESULTS AND DISCUSSIONS}

\section{$168 \quad$ 3.1 The Free-standing film thickness and Birefringence measurements}

169 The temperature dependence of the thickness of a free-standing film (FSF) is studied using a 170 high-resolution interferometric measurement technique [27]. A good quality homeotropic 171 alignment of LC molecules is achieved in the FSF of $\mathrm{MSi}_{3} \mathrm{MR} 11$, the layer thickness covers $172 \sim 10,000$ layers. An experimental measurement is carried out by shining an unpolarized beam 173 of light along the layer normal. Both heating and cooling cycles of the sample were carried 
out with rates as low as $0.01^{\circ} \mathrm{C} / \mathrm{min}$ in order to avoid the change in the thickness that would occur by a possible destruction of a few layers of the sample when the heating/cooling rates were large enough. Figure 4 shows temperature dependence of the optical film thickness normalized to the thickness at the SmA-SmC phase transition for the compound under study. The optical film thickness is defined as its mechanical thickness multiplied by its effective refractive index. The thickness is measured with a high resolution interferometric technique to an accuracy better than $0.01 \%$. If one simulates the refractive index with a change in the tilt angle, then the normalized or the relative layer thickness can be obtained. Below the isotropic temperature, the film thickness initially increases linearly but with a reduction in temperature [28] and on approaching the smectic $\mathrm{A}^{*}-\mathrm{SmC}$ transition, the film thickness reverses its trend from increasing to decreasing with a reduction in temperature due to an onset of the tilt. This trend characterizes $\mathrm{SmA}^{*}-\mathrm{SmC}^{*}$ transition. For $\left(\mathrm{T}-\mathrm{T}_{\mathrm{AC}}\right)$ varying from zero to $-0.61{ }^{\circ} \mathrm{C}$, as seen in Fig. 4 , a change in the normalized film thickness shows a sharp decrease with a large drop-off in thickness. This anomalous drop is the characteristic evidence for the first order SmA* - SmC* phase transition, labelled in Fig. 4 as the region where $\mathrm{SmA}^{*}$ and $\mathrm{SmC}^{*}$ coexist. If all the layers in this narrow temperature range were to be in the $\mathrm{SmC}^{*}$ alone, the optical film thickness would have exhibited rather a linear low slope drop-off with temperature; contrary to what is observed here. As already stated, the firstorder behavior is additionally corroborated by the DSC observations at the $\mathrm{SmA}^{*}$ to $\mathrm{SmC}^{*}$ transition (Fig. 2b), which shows it to be a weak first-order transition. On further cooling the film in the $\mathrm{SmC}^{*}$ phase, its thickness continues to decrease only relatively slightly due to an increase in the tilt angle. Finally the layer thickness reaches $d_{C} \approx 0.9925 d_{A C}$ at $6.3{ }^{\circ} \mathrm{C}$ below $\mathrm{T}_{\mathrm{AC}}$. In this material, the layer shrinkage of $0.75 \%$ is found to be close to the reported values of $0.73 \%$ and $0.65 \%$ for the other known de-Vries materials: W599 [21] and TSiKN65 [20], respectively. This small layer shrinkage is due to an increase in the tilt angle with a reduction in temperature; it is small because in going from $\mathrm{SmA}^{*}$ to $\mathrm{SmC}^{*}$, the in-layer directors with azimuthal angles degenerated and distributed on to a cone in SmA* condense on to the azimuthal angles lying within narrower limits of the tilt in the $\mathrm{SmC}^{*}$ phase (see Fig. 1b); this process on its own requires no change in the layer thickness. 


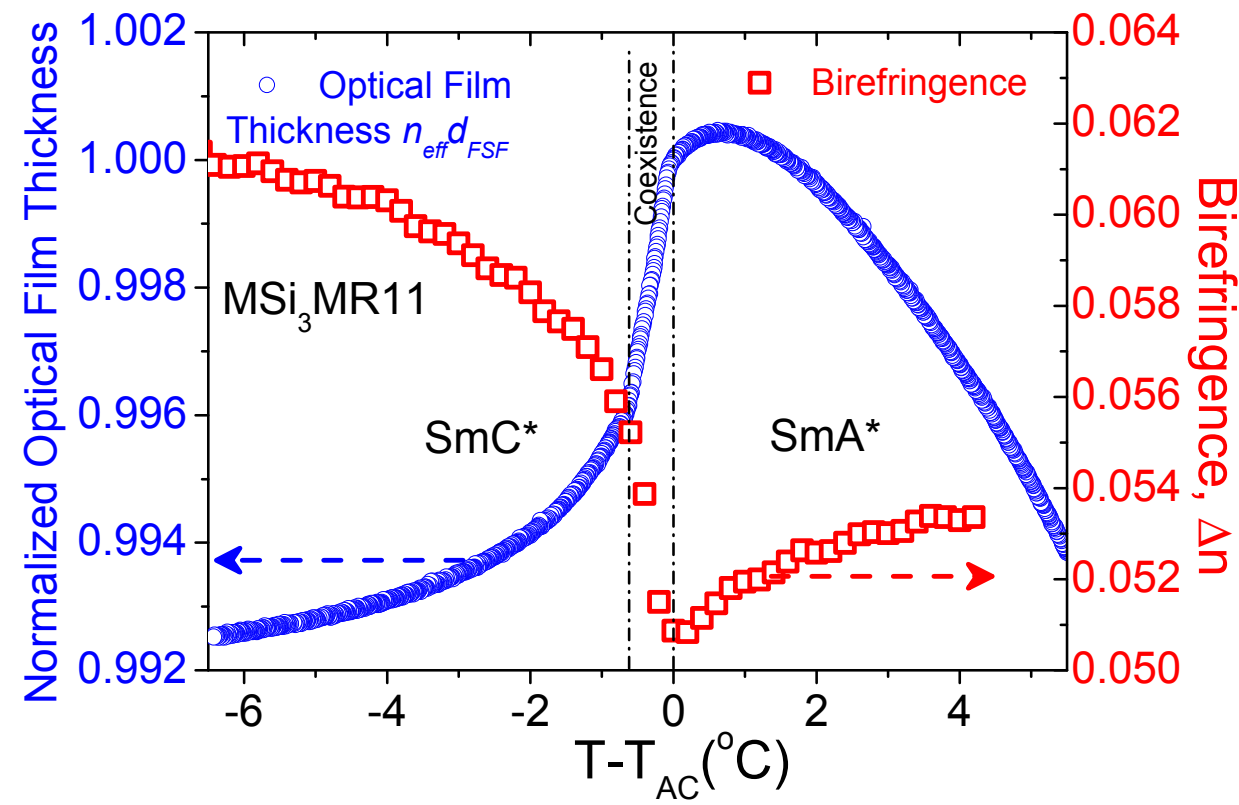

FIG. 4: (color online) Temperature dependence of the normalized optical film thickness; plotted as circles ( ). Birefringence as squares, $\square$, plotted as a function of temperature on the right-hand side of Fig. 4. Measurements of the birefringence are carried out in the absence of external field on a $3 \mu \mathrm{m}$ planar cell under cooling from the isotropic state. The coexistence region shown by two vertical dotted lines, where the two phases co-exist, is the signature of the first-order phase $\mathrm{SmA}^{*}-\mathrm{SmC}^{*}$ phase transition. In this narrow temperature range, if all the layers were to be in the $\mathrm{SmC}^{*}$ alone, the optical film thickness would have shown a small linear drop-off with temperature.

Figure 4 also shows the plots of the apparent birefringence $\Delta n$ and the optical layer thickness as a function of $\left(\mathrm{T}-\mathrm{T}_{\mathrm{AC}}\right)$.The magnitude of $\Delta n$ first decreases on cooling and then starts to increase after the $\mathrm{SmA}^{*}-\mathrm{SmC}^{*}$ phase transition has occurred [29]. The decrease in $\Delta n$ is due to the de-Vries tilt appearing in the $\mathrm{SmA}^{*}$ phase where the in-layer directors are distributed on the cone. Values of the birefringence, $\Delta n$, and the apparent optical tilt angle, $\theta_{\mathrm{App}}$, are determined by recording the transmitted beam of light through the LC sample where a set of crossed polarizer and analyzer is rotated using a procedure similar to that described by Park et al. [30]. Experiments were conducted by applying a triangular signal of frequency $46 \mathrm{~Hz}$ and an amplitude of $16 \mathrm{~V}_{0-\mathrm{pk}} / \mu \mathrm{m}$. The frequency is so chosen as to allow sufficient time for switching to occur while avoiding the ionic conductivity from contributing to the switching current, and different from the mains frequency of $50 \mathrm{~Hz}$ to avoid interference from electrical noise to the output signal. Amplitude of the voltage applied should be large enough to saturate the tilt angle but at the same time it should be such be much lower than the dielectric breakdown of the sample by the electric field. 
The field-induced tilt angle $\theta_{\mathrm{App}}$ and $\Delta n$ values for selected temperatures close to the SmA* - $\mathrm{SmC}^{*}$ transition are plotted as a function of the applied field in Fig. 5. Magnitude of $\Delta n$ increases with electric field (Fig. 5a) due to the lifting of degeneracy in azimuthal angle with the field. The behavior is typical of the diffuse-cone class of models for the SmA* phase. The tilt angle increases by the conventional electroclinic effect first and then finally it gets saturated

232 with the field. This saturation in the tilt angle occurs in both $\mathrm{SmC}^{*}$ and in the temperature range 233 of $\mathrm{SmA}^{*}$ closer to the $\mathrm{SmA}^{*}-\mathrm{SmC}$ * transition. At higher temperatures in the SmA* phase, the 234 electroclinic effect itself is small and hence the electric fields applied are not large enough for 235 the saturation in $\theta_{\text {App }}$ to show up; here $\theta_{\text {App }}$ shows almost linear response to the applied electric 236 field [31] up to the value of $\theta_{\mathrm{App}} \sim 15^{\circ}$. For temperatures closer to the $\mathrm{SmC} * \mathrm{SmA}$ * transition 237 temperature, $\theta_{\text {App }}$ slightly deviates from the linear dependence on moderate values of the field, 238 thus having a positive value of the second derivative with field. For large values of the electric 239 field, $\theta_{\text {App }}$ continues to grow slowly and its second derivative becomes negative. Since the 240 sigmoidal response of $\theta_{\mathrm{App}}(E)$ and $\Delta n(E)$ could not be satisfactorily explained by Fukuda's 241 Langevin-Debye approach [32], Shen et al. [21] proposed a modified model where they added 242 additional term involving square of the electric field in the expression for the free energy.

243

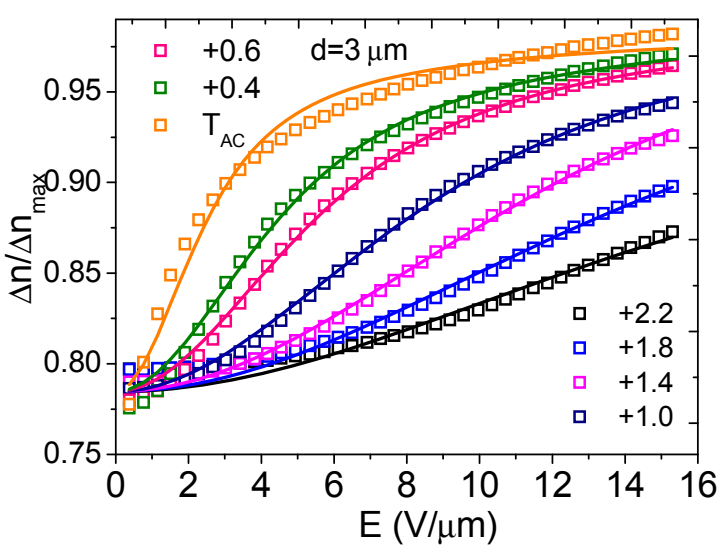

5(a)

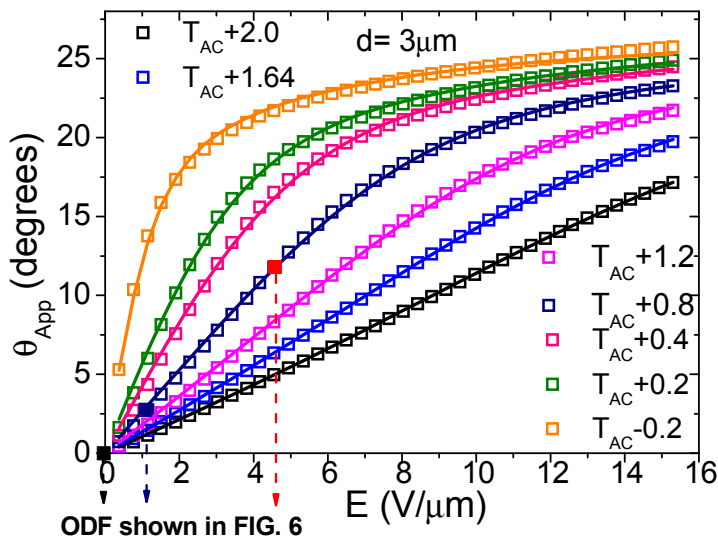

5(b) 


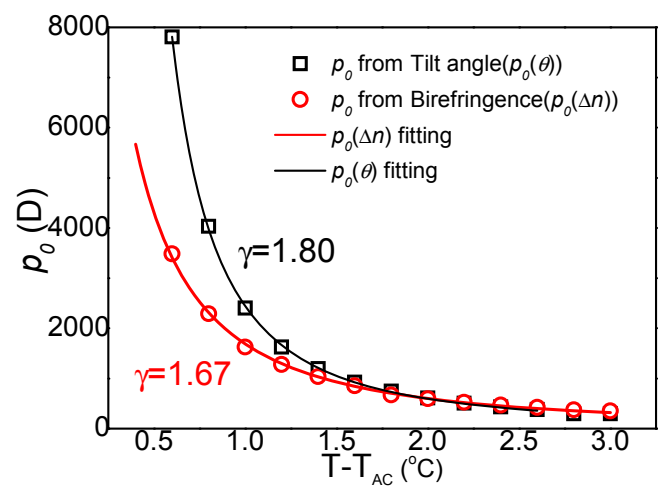

5(c)

FIG. 5: (color online) (a) Measured values of the birefringence as a function of the electric field are fitted to the generalized Langevin-Debye model (solid lines) [21], (b) the field induced optical tilt (experimental values in symbols) are fitted to this model (solid lines). Data points for the Orientational distribution function (ODF) to be shown in Fig. 6 are marked in Fig. 5b. (c) The local dipole moment $p_{0}$ obtained from ( $\Delta n$ and $\theta_{\text {App }}$ fits) as a function of the reduced temperature. The solid lines are the best fits to the power law equation for the total dipole moment $p_{0}(\mathrm{~T})=\mathrm{A} /\left(\mathrm{T}-\mathrm{T}_{\mathrm{AC}}\right)^{\gamma} ; \gamma$ is the power law exponent.

Inspite of the several approaches [32-36] that exist for modeling the unusual electro-optic characteristics of the de-Vries compounds; we choose the generalized Langevin-Debye model that was recently proposed by Shen et al. [21] for the better analysis of our data for the reasons given above. Fit of the data to the model leads to the orientational distribution function (ODF), with a complete azimuthal degree of freedom but the tilt $\theta$ is allowed to vary by the applied field within a certain range of values. A quadratic term in the electric field in the expression of free energy has been found to have significantly improved the fit of the experimental data to the model. According to this model the free energy, $U$, is expressed as:

$$
U=-\boldsymbol{p}\left(1+\alpha \frac{\boldsymbol{p}}{|\boldsymbol{P}|} \cdot \boldsymbol{E}\right) \cdot \boldsymbol{E}=-p_{0} E \sin \theta \cos \varphi(1+\alpha E \cos \varphi)
$$

Here $p=p_{0} \sin \theta$ is the dipole moment of the domain correlated in the tilt brought about by the condensation of the azimuthal angle. The first term $\left(-p_{0} E \sin \theta \cos \varphi\right)$ given in Eqn. 1 describes the dipole interaction energy and the second term $\left(-p_{0} E^{2} \sin \theta \cos ^{2} \varphi\right)$ includes the tilt susceptibility that increases with the square of the electric field. This term leads to the sigmoidal response in both $\Delta n$ and $\theta_{A p p}$ with applied field. $\alpha$ is the phenomenological scaling factor. The tilt angle $\theta_{A p p}$ and the birefringence $\Delta n$ as functions of the applied field become: 


$$
\frac{\Delta n}{\Delta n_{\max }}=\frac{\left\langle\cos ^{2} \theta-\sin ^{2} \theta \cos ^{2} \varphi\right\rangle}{\cos 2 \theta_{A p p}}
$$

274

275

276

277

278

279

280

281

282

283

284

285

286

An average $\langle Y\rangle$ is estimated over the orientational distribution of molecules according to the formula $\langle Y\rangle=\int_{\theta_{\min }}^{\theta_{\max }} \int_{0}^{2 \pi} Y(\theta, \varphi) f(\theta, \varphi) \sin \theta d \theta d \varphi$, where the mean field orientational distribution function $f(\theta, \varphi)$ is expressed as $f(\theta, \varphi)=\exp \left[-U / k_{B} T\right] / \int_{\theta_{\min }}^{\theta_{\max }} \int_{0}^{2 \pi} \exp [-U /$ $k B T \sin \theta d \theta d \varphi$ [21]. In this model, the field induced angle varies between the values inferred from the birefringence at zero electric field $\left(\theta_{\min }\right)$ to the maximum field $\left(\theta_{\max }\right)$. For the latter $\Delta n$ is assumed to be saturated by the field. Here, for MSi3MR11, the limiting values of the induced angle are found to be $\theta_{\min }=16.93^{\circ}$ and $\theta_{\max }=26.63^{\circ}$ (Fig. 5a, b). These limiting values of $\theta$ themselves are temperature independent but the actual value within these limits is nevertheless temperature dependent. Datasets obtained for both $\Delta n(E)$ and $\theta_{\text {App }}(E)$ are fitted by the model [21]. However in contrast to the procedure used in [21], the fitting is carried out separately for both $\Delta n(E)$ and $\theta_{\mathrm{App}}(E)$. Though better fits for both (a) and (b) are obtained, however the fits with different power law exponents do reveal short-comings of the model. However both exponents are in the "de Vries - range" and outcome of the ODF is clearly "diffused-cone". If such a limation is material independent then this issue needs to be addressed in future.

Figure 6 shows the 'orientation distribution function' (ODF), $f(\theta, \varphi)$, for $\mathrm{MSi}_{3} \mathrm{MR}_{11} 1$ at a temperature of $\mathrm{T}=\left(\mathrm{T}_{\mathrm{AC}}+0.8\right){ }^{\circ} \mathrm{C}$ for different strengths of the electric field. The simulated ODF is rather close to a corresponding result demonstrated earlier for a different material (Fig. 5 (a,b) in ref [21]). One can see that the model enforces a clear diffused cone distribution - by confining the cone angle between the limits of $\theta_{\min }$ and $\theta_{\max }$. In this case, the re-distribution of the azimuthal angles of molecules caused by the electric field generates a finite apparent optical tilt angle very close to the one found in the experiment (Fig. 5b). For the higher field strengths, nearly all of the molecules are aligned along a single direction on the outer $\left(\theta_{\max }\right)$ cone. Note that the modelled ODF shown in Fig. 6 corresponds to the aromatic core part of the molecule that exhibits birefringence in the visible range of wavelengths. 


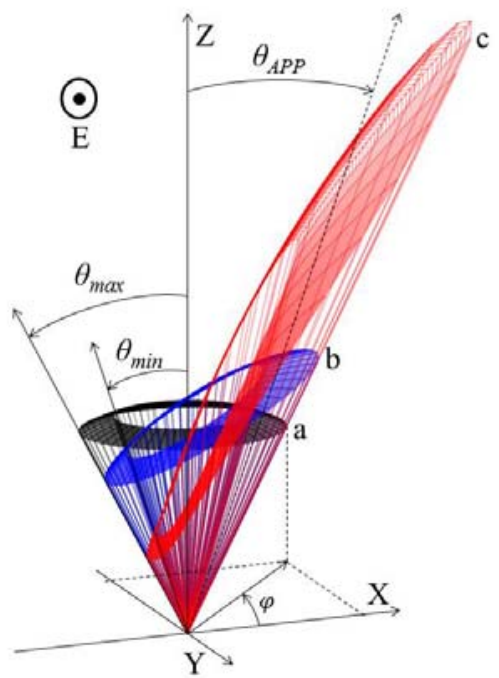

299

300

301

302

303

304

305

FIG. 6 (color online): The Orientation Distribution Function $f(\theta, \varphi)$ of $\operatorname{MSi}_{3} \mathrm{MR} 11$ at a temperature of $\mathrm{T}=\left(\mathrm{T}_{\mathrm{AC}}+0.8\right){ }^{\circ} \mathrm{C}$ for various values of electric field strengths - (a) $0 \mathrm{~V} / \mu \mathrm{m}$ (black); (b) $1.14 \mathrm{~V} / \mu \mathrm{m}$ (blue); and (c) $4.17 \mathrm{~V} / \mu \mathrm{m}$ (red). $X-Y$ is the smectic layer plane and $Z$ is directed along the layer normal. Electric field is applied along the $Y$ direction which lies in the smectic layer.

The local dipole moment $p_{0}$, (Fig. 5c), determined as a fitting parameter increases with decreasing temperature in the $\mathrm{SmA}^{*}$ phase. On approaching the $\mathrm{SmA}^{*}-\mathrm{SmC}^{*}$ transition from the high temperature side, the magnitude of $p_{0}$ in the generalized Langevin-Debye model diverges corresponding to the correlation length of the tilt domain where the azimuthal angle is condensed to values within narrow limits. Here the magnitudes of $p_{0}$ obtained from the fitting of the birefringence and the tilt data are somewhat different in the vicinity of the smectic SmA* SmC* transition. Also, the scaling parameter $\alpha$ of the electric field varies from 0.017 to 0.023 $\mu \mathrm{m} / \mathrm{V}$ for birefringence and $\sim 0.024$ to 0.11 for data on the tilt angle. This clearly indicates that the system is more complex than the simple assumptions made in this model despite the quality of the individual fits of $\Delta \mathrm{n}$ and the apparent tilt angle to the model. One of the main reasons for this discrepancy could be that the model assumes constant values of $\theta_{\min }$ and $\theta_{\max }$ independent of temperature. But measurements on the layer thickness and on temperature dependence of the zero-field birefringence reveal that $\theta_{\min }$ does at least vary with temperature. The second reason could be that the molecular biaxiality that is neglected in the model so far has to be taken into account [33].

To analyze the temperature dependence of the correlated dipole moment, $p_{0}$, we fit the data to the power law equation, $p_{0}(\mathrm{~T})=\mathrm{A} /\left(\mathrm{T}-\mathrm{T}_{\mathrm{AC}}\right)^{\gamma}$ (Fig. 5c), $\gamma$ is the power law exponent. The fit is found to be excellent but temperature dependencies of the local dipole moment are 

to be 1.67 and 1.80 , respectively. These fits lead to the conclusion that the correlated tilt (or the correlation length) increases with a reduction in temperature in the $\mathrm{SmA}^{*}$ phase [37], this is reminiscent of the de-Vries behavior $[9,18]$.

\subsection{X-ray Diffraction}

The $\mathrm{x}$-ray diffraction pattern for the $\mathrm{SmA}^{*}$ shows sharp Bragg layer reflection peaks in the small angle region centered at $\sim 39.6 \AA$ and the $2^{\text {nd }}$ order reflection centred at $\sim 19.8 \AA$, shown in Fig. 7a. A pair of diffuse crescents in the wide-angle region perpendicular to the layer peak located at $\sim 4.6 \AA$ confirm the orthogonal smectic $(\mathrm{SmA})$ nature of this phase. In the $\mathrm{SmC}^{*}$ phase (Fig. 7b), the $3^{\text {rd }}$ order smectic reflections appear at $\sim 13.4 \AA$ and the crescents are centered at 4.6 $\AA$ perpendicular to the layer peaks, this seems to be indistinguishable from the SmA* phase. However, the pair of wide-angle crescents are more diffuse in the $\mathrm{SmC}^{*}$ phase, than in $\mathrm{SmA}^{*}$, where each crescent can be approximated as a sum of the two crescents separated by an angle $2 \alpha$, $\alpha$ being the molecular tilt angle with respect to the layer normal. This corresponds to the domain structure with the opposite tilts, as illustrated in the inset of Fig. $7 \mathrm{~b}$.
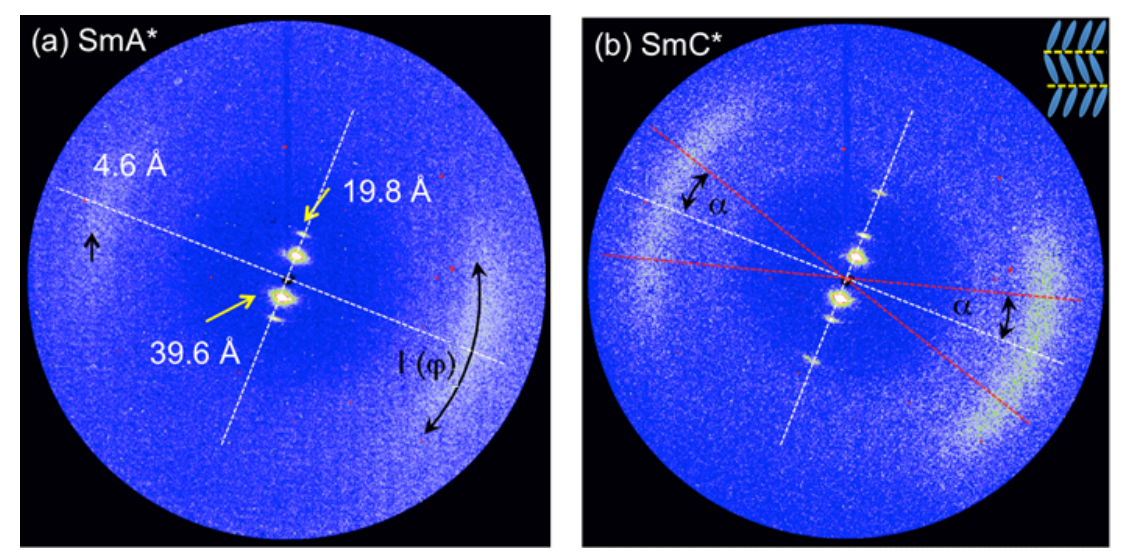

Fig. 7: Representative x-ray diffractions patterns of MSi3MR11 in (a) SmA* phase $\left(1.2{ }^{\circ} \mathrm{C}\right.$ above the $\left.\mathrm{T}_{\mathrm{AC}}\right)$ and (b) $\mathrm{SmC}^{*}$ phase $\left(17.5^{\circ} \mathrm{C}\right.$ below the $\left.\mathrm{T}_{\mathrm{AC}}\right)$. Inset of $(\mathbf{b})$ depicts the $\mathrm{SmC}^{*}$ structure.

The temperature dependence of the smectic layer spacing (Fig. 8a), determined from the 344 SmC* $^{*}$ phase, approximately 20 degrees below the smectic $A^{*}$ to $C^{*}$ transition. Note that the optical layershrinkage of $0.75 \%$ mentioned above is based on the smallest $d_{C}$ spacing, obtained approximately 6 degrees below the smectic AC transition. The inset in Fig. 8a shows a comparison between the layer thickness measured by x-ray with the optical FSF thickness, the 
latter is normalized by the value at the $\mathrm{SmA}^{*}$ to $\mathrm{SmC}^{*}$ transition temperature. A different trend in between the two is due to a change in the refractive index tensor by the molecular tilt angle $\theta$ [27]. On cooling the cell in $\mathrm{SmC}^{*}$ this deviation reaches $\sim 20 \%$ of the total shrinkage which can

351

352

353

354

355

356

357

358

359

360

361

362

363

364

365

366

367

368

369

370

371

372

373

374

be explained by a larger value of the tilt at the phase transition point as compared to the material described in [27]. The tilt angle, $\alpha$ in the $\mathrm{SmC}^{*}$ phase was calculated as half the angle of separation between the centers of the two Gaussian fits to the azimuthal intensity distribution, $I(\varphi)$ of the wide angle reflection at $4.6 \AA$, Fig. $8 \mathrm{~b}$. Owing to the difficulty in obtaining a single domain sample, a reasonable temperature dependence of the tilt angle in the $\mathrm{SmC}^{*}$ phase specifically close to the $\mathrm{SmA}^{*}-\mathrm{SmC}^{*}$ transition was difficult to determine. Nonetheless, the maximum calculated tilt angle $\alpha_{\max }$ is $\sim 20^{\circ}$ in the lower $\mathrm{SmC}^{*}$ phase.

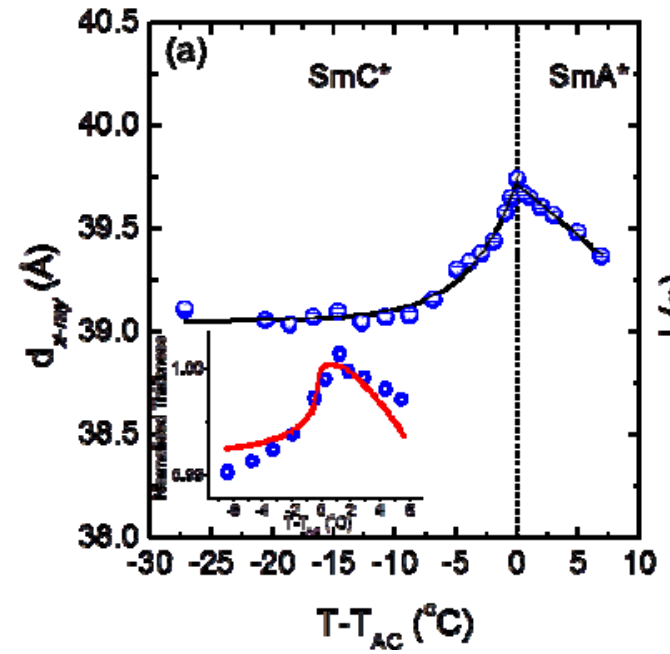

(a)

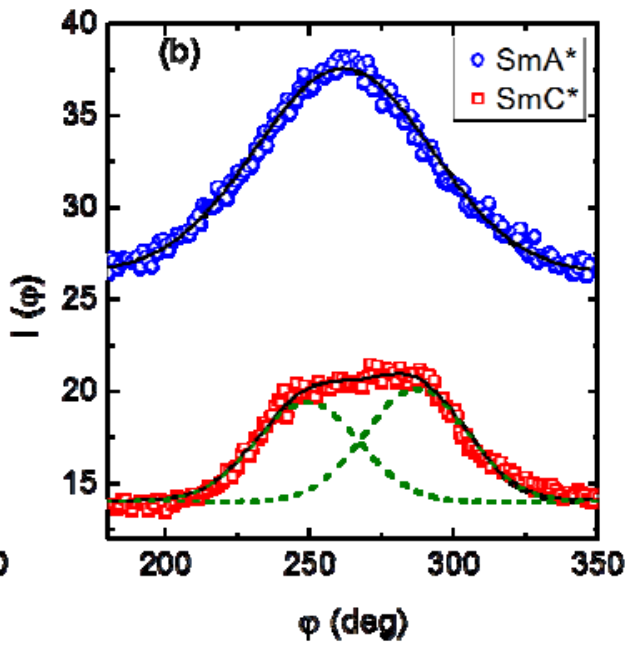

(b)

FIG. 8. (color online): (a) Temperature dependence of the layer spacing determined from the x-ray diffraction. A comparison of the results of the layer thickness from the free standing film experiment (red solid line) and the layer thickness from the x-ray results as discrete points (circles) given in the inset. Both curves in the inset are normalized (b) The representative azimuthal intensity distribution $I(\varphi)$ of the wideangle reflection centered at $4.6 \AA$ in the $\mathrm{SmA}^{*}$ (open circles) and in the $\mathrm{SmC}^{*}$ (open squares) phases. The solid black line in $\mathrm{SmA}^{*}$ is a single Gaussian fit (FWHM=64), while in $\mathrm{SmC}^{*}$, it is the sum of two Gaussian fits (dashed-lines) with $\mathrm{FWHM}=36$.

The orientational order parameter, $\left\langle\mathrm{P}_{2}(\cos \beta)\right\rangle$ from the azimuthal intensity distribution $I(\varphi)$ of the wide angle reflection centered at $\sim 4.6 \AA$ (Fig. 7b) is determined using the method of Davidson et al. [38], numerical inversion method increased the value from $0.41 \pm 0.01\left(\mathrm{SmA}^{*}\right)$ to $0.58 \pm 0.01$ (SmC*). Here, $\beta$ corresponds to the angle between the director and the long axis of the molecule. The low values of $\left\langle\mathrm{P}_{2}\right\rangle$ obtained here are the typical ones for the de-Vries compounds with chiral components, as compared to the $\left\langle\mathrm{P}_{2}\right\rangle$ for de-Vries without chiral components $[12,13]$, however these low values are also partly attributed to the presence of multi 
375 domains in the scanned sample volume. Correspondingly, the average molecular fluctuation [13] $376\langle\beta\rangle$, decreased from $35.8^{\circ} \pm 0.2\left(\mathrm{SmA}^{*}\right)$ to $31.6^{\circ} \pm 0.2\left(\mathrm{SmC}^{*}\right)$. The extent of molecular 377 fluctuations in $\mathrm{SmA}^{*}$ is much larger than the measured maximum apparent tilt, $\theta_{\mathrm{App}} \sim 25^{\circ}$ which 378 obscures the dip in the expected volcano-shaped ODF for de-Vries compounds and effectively 379 appears as sugarloaf distribution shown in Fig. 9 as a solid line. To illustrate this, a simulated 380 orientational distribution function ODF with respect to the layer normal in de-Vries SmA phase 381 with a polar tilt angle $\alpha=25^{\circ}$ and the molecular fluctuations $\langle\beta\rangle \sim 23^{\circ}$ is also shown in Fig. 9 (red 382 dashed line). Note that the x-ray diffraction probes the electron density related to the overall 383 molecular length, thus the sugarloaf-shaped ODF obtained from the x-ray experiment does not rule out the diffuse-cone distribution obtained from the visible light optical parameters of the 385 same compound.

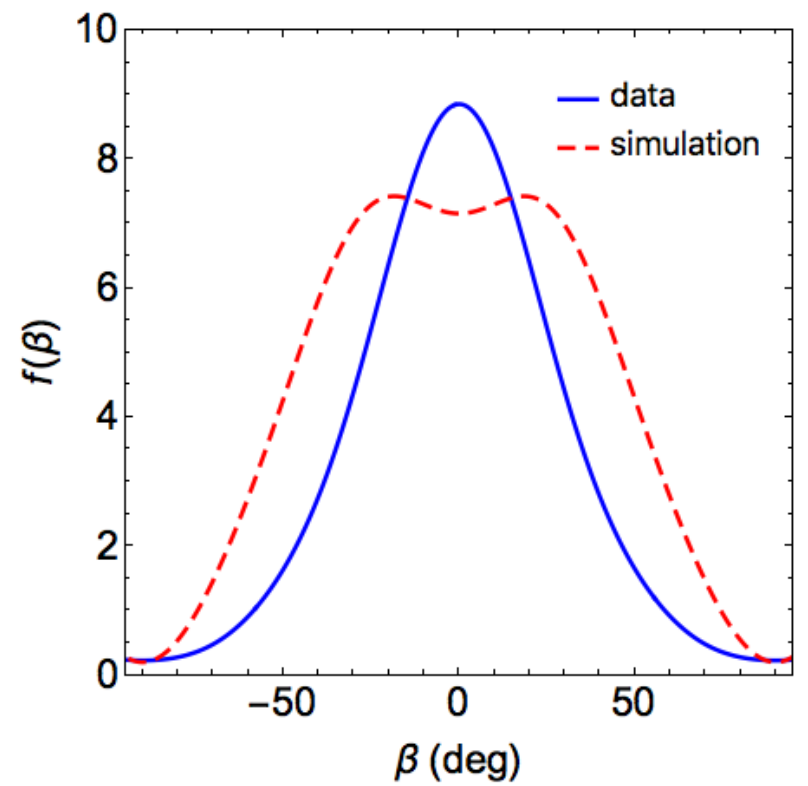

387

388

389

390

\section{1}

392

393

394

395

396

397
FIG. 9. (color online) The orientational distribution functions in the $\mathrm{SmA}^{*}$ phase determined from the experimentally measured $I(\varphi)$ (solid line) and the simulation (red dashed line).using molecular fluctuations $\langle\beta\rangle=23^{\circ}$ and the tilt angle $\alpha=25^{\circ}$

\subsection{Spontaneous Polarization Measurement}

The spontaneous polarization $\boldsymbol{P}_{\boldsymbol{S}}$ is measured using a planar cell of thickness $4 \mu \mathrm{m}$ as a function of temperature and the results are shown in Fig. 10. For conducting the experiment, an external triangular wave ac voltage of $50 \mathrm{~V}_{\mathrm{pk} \text {-pk }}$ of frequency $152 \mathrm{~Hz}$ is applied across the planarly aligned cell using the method reported previously [39]. Measured value of Ps corresponds to its saturated value by the external field at the temperature of interest . The LC under study gives $\boldsymbol{P}_{\boldsymbol{S}}$ $\sim 124 \mathrm{nC} \mathrm{cm}^{-2}$ for a temperatiure of $\mathrm{T}=\left(\mathrm{T}_{\mathrm{AC}}-13.5\right){ }^{\circ} \mathrm{C}$. 


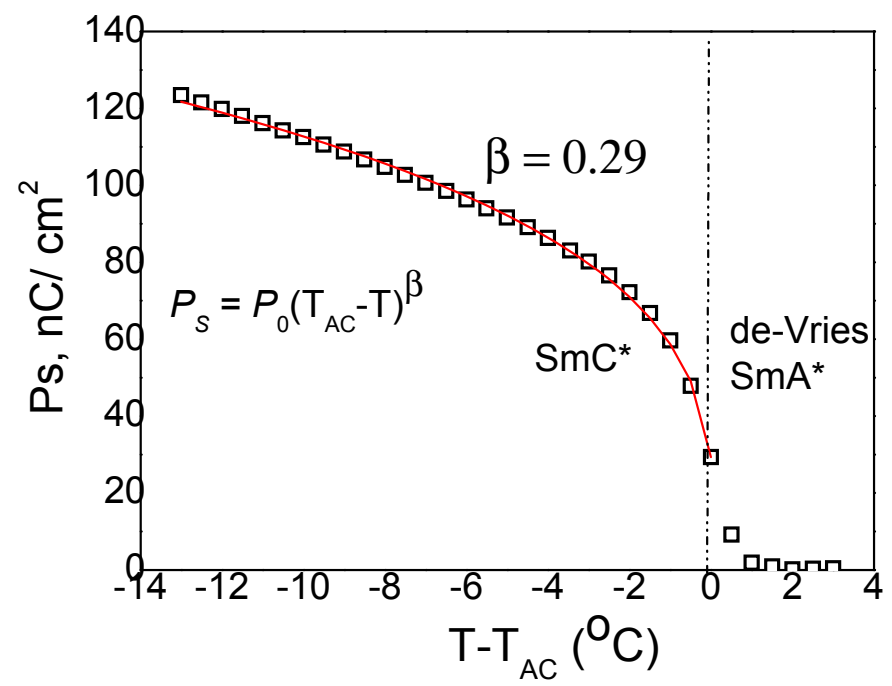

398

399 FIG. 10. (color online) Spontaneous polarization $\boldsymbol{P}_{\boldsymbol{S}} v s\left(\mathrm{~T}-\mathrm{T}_{\mathrm{AC}}\right)$ measured on $4 \mu \mathrm{m}$ planar cell 400 under cooling from the isotropic state. A triangular-waveform voltage of $50 \mathrm{Vpk}$ to pk at a frequency of $152 \mathrm{~Hz}$ is used in the experiment. $P_{0}=56.9 \mathrm{nC} . \mathrm{cm}^{-2}$.

402

$403 P s$ values are fitted to the power law equation $P_{S}=P_{0}\left(T_{A C}-T\right)^{\beta}$. In the fitting, it is not

404 possible to include the values $P S$ in the SmA phase. The power law exponent, $\beta=0.29$, is

405 found from the fitting. This value so determined is close to that for the tricritical behavior; i.e.

406 the point where the first and second order transitions meet with each other. The transition can

407 then be described as 'a weakly first order transition'.

\section{$408 \quad 3.4$ Dielectric Spectroscopy}

409 Figure 11a shows the three dimensional plot of temperature dependent dielectric loss 410 spectra $\left(\varepsilon^{\prime \prime}\right)$ of a planarly-aligned cell filled with $\mathrm{MSi}_{3} \mathrm{MR} 11$. The electrodes are made up of 411 brass, these are gold-plated so as to have almost zero contact resistance. This is done to avoid the 412 parasitic effects of the finite resistance of ITO electrodes acting in series with the cell413 capacitance on the dielectric spectra.

414 


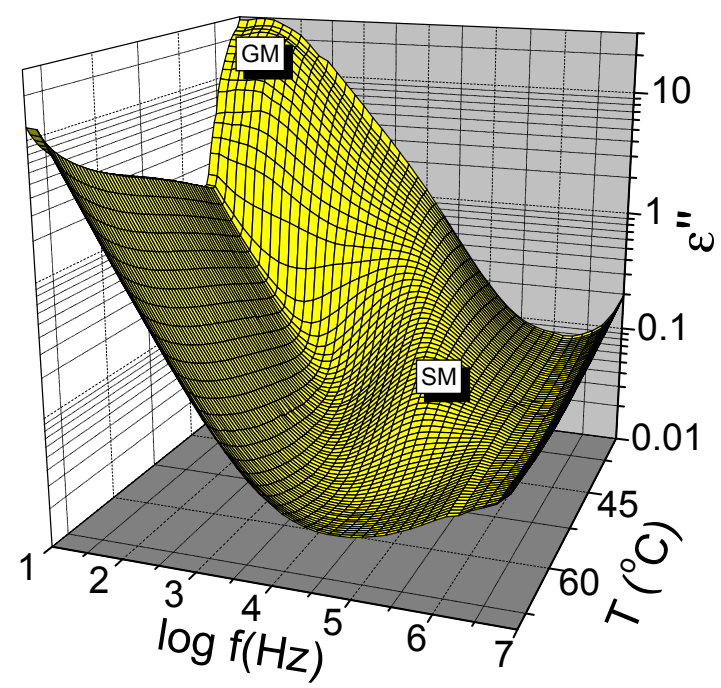

(a)

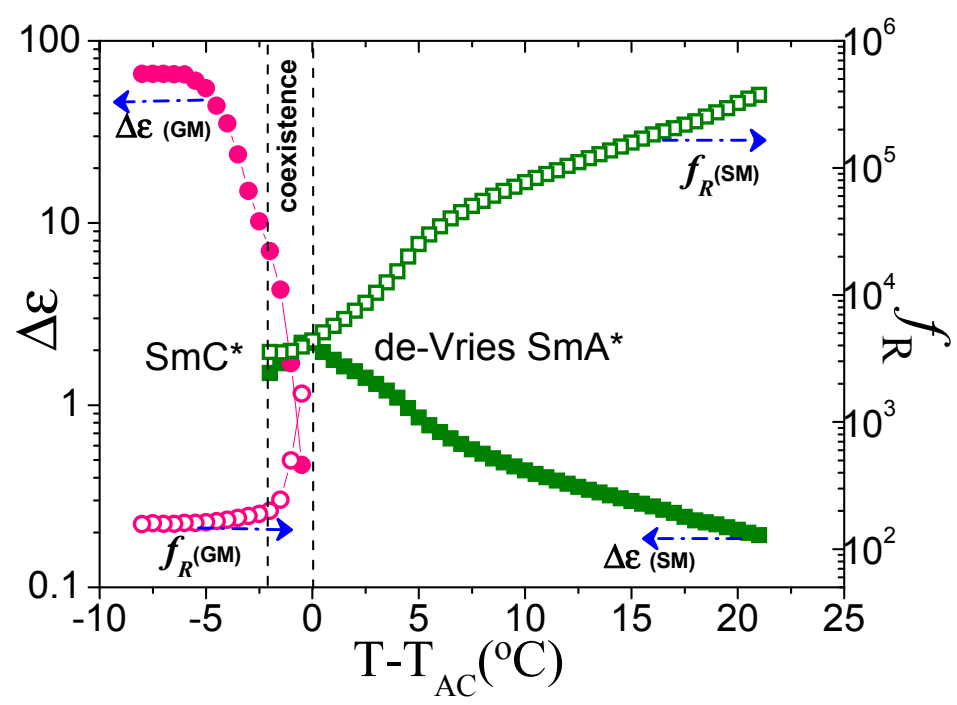

(b)

FIG. 11. (color online) (a) The three dimensional (3D) plot of temperature dependent dielectric loss spectra $\left(\varepsilon^{\prime \prime}\right)$ for a $10 \mu \mathrm{m}$ planarly aligned cell in the frequency range $1 \mathrm{~Hz}$ $10 \mathrm{MHz}$. The dielectric measurements are carried out on the sample under cooling from the isotropic state. Temperature is stabilized to $\pm 0.05{ }^{0} \mathrm{C}$ and the applied voltage in the experiment is fixed as $0.1 \mathrm{~V}_{\text {rms. }}$. (b) The dielectric relaxation strength $\Delta \varepsilon$ and the relaxation frequency $f_{R}$ for both the Goldstone (GM) and soft (SM) modes are plotted as a function of the reduced temperature. The temperature range where the two phases coexist is shown by a set of vertical dotted lines close to the transition temperature.

The dielectric measurements are carried out over a frequency range of $1 \mathrm{~Hz}$ to $10 \mathrm{MHz}$ using a broadband Alpha High resolution Dielectric analyser (Novocontrol GmbH, Germany), measurement made under a weak applied voltage of $0.1 \mathrm{~V}_{\text {rms }}$. Temperature of the cell is controlled to within $\pm 0.05{ }^{\circ} \mathrm{C}$. The temperature dependencies of the dielectric strength $(\Delta \varepsilon)$ and 
432 the relaxation frequency $\left(f_{R}\right)$, are obtained by fitting the dielectric spectra to the Havriliak 433 Negami equation [40]:

$$
\varepsilon^{*}(\omega)=\varepsilon^{\prime}-i \varepsilon^{\prime \prime}=\varepsilon_{\infty}+\sum_{j=1}^{n} \frac{\Delta \varepsilon_{j}}{\left[1+\left(i \omega \tau_{j}\right)^{\alpha_{j}}\right]^{\beta_{j}}}-\frac{i \sigma_{d c}}{\varepsilon_{0} \omega}
$$

Here, $\varepsilon_{\infty}$ is the high frequency permittivity that includes the atomic and electronic polarizabilities, $\mathrm{j}$ is the number of relaxation processes and it varies from 1 to $n, \omega=2 \pi f$ is the angular frequency, $\varepsilon_{0}$ is the permittivity of free space, $\Delta \varepsilon_{\mathrm{j}}$ refers to the dielectric relaxation strength of the jth mode. $\alpha_{j}\left(0<<\alpha_{j} \leq 1\right)$ and $\beta_{j}\left(0<<\beta_{j} \leq 1\right)$ are the symmetric and asymmetric broadening parameters of the complex dielectric function of the $\mathrm{j}^{\text {th }}$ relaxation process. The $\sigma_{\mathrm{dd}} / \varepsilon_{0} \omega$ is contribution of the dc conductivity to $\varepsilon^{\prime \prime}$. The relaxation frequency, $f_{j}$, of the $j^{\text {th }}$ relaxation process is related to its relaxation time $\tau_{j}$ as [41]:

$$
f_{j}=\frac{1}{2 \pi \tau_{j}}\left[\frac{\sin \left(\alpha_{j} \pi\right)}{2+2 \beta_{j}}\right]^{1 / \alpha_{j}}\left[\frac{\sin \left(\alpha_{j} \beta_{j} \pi\right)}{2+2 \beta_{j}}\right]^{-1 / \alpha_{j}}
$$

In this case we fix $j=2$ as we focus on to the two predominant modes: Goldstone mode (GM) and the soft mode (SM) over a restricted range of frequencies; inspite of the fact that many additional modes can possibly exist in a FLC cell [42]. The dielectric spectra are analysed using WINFIT programme purchased from Novocontrol GmbH. Temperature dependencis of the dielectric strength $(\Delta \varepsilon)$ and relaxation frequency $\left(f_{R}\right)$ for the two modes are shown in Fig. $11 \mathrm{~b}$. On cooling the cell from the isotropic state, the amplitude of the $\Delta \varepsilon$ increases and reaches a maximum value at the $\mathrm{SmA}^{*}-\mathrm{SmC}^{*}$ phase transition. The corresponding $f_{R}$ decreases on cooling over a broad temperature range of SmA* phase but with a sharper trend in its lower temperature range. In the studied chiral MSi3MR11 material, the soft mode fluctuation is dielectrically active in the $\mathrm{SmA}^{*}$ phase due to the component of the dipole moment parallel to the probe field fluctuating with the applied electric field. Remarkably strong soft mode absorption is found in the dielectric spectra of de-Vries materials over a broader temperature range in comparison to the materials that exhibit a conventional SmA phase. For example the dielectric strength rises continuously with a reduction in temperature in this sample as opposed to a sudden rise of $\Delta \varepsilon$ in a conventional SmA phase, [compare Fig. 11b with Fig. 1b of Ref. 43] and Fig. 11b with Fig. 8a and $8 \mathrm{~b}$ of [44]. Similarly the soft-mode relaxation frequency continuously decreases over a very wide temperature range in $\mathrm{SmA}^{*}$ in this sample as opposed to conventional $\mathrm{SmA}$ in which a sudden change in the frequency occurs over a very narrow 
461 range of temperatures close to the $\mathrm{SmA}^{*}-\mathrm{SmC}^{*}$ transition [compare Fig. 11b with Fig $1 \mathrm{~b}$ of $462[43]]$ for the relaxation frequency.

463

464 4. CONCLUSIONS

465 The siloxane liquid crystalline compound exhibiting de-Vries SmA* phase was studied by DSC, 466 polarizing optical microscopy, XRD, FSF, electro-optics and dielectric spectroscopy. MSi ${ }_{3} \mathrm{MR} 11$ 467 shows a direct transition to $\mathrm{SmA}^{*}$ phase on cooling from the isotropic state. Calorimetric studies 468 confirm earlier works on the LC thermograms that report first order $\mathrm{SmA}^{*}$-SmC* phase 469 transition in de-Vries LCs. Based on the results of $\Delta n$ and $\theta_{\text {App }}$ measurements, together with the 470 minimum layer shrinkage $(\sim 1.75 \%)$ obtained in this case, we characterize $\mathrm{SmA}^{*}$ of the studied 471 material to be of the de-Vries type, since an increase in the tilt angle with reducing temperature 472 leads to decrease in magnitude of the birefringence. An increasing $\Delta n$ with applied field was 473 found in the vicinity of $\mathrm{SmA}^{*}$-SmC* transition. The generalised Langevin-Debye model as 474 proposed by Shen et al. [21] is used to explain the electro-optical effects observed 475 experimentally in the de-Vries $\mathrm{SmA}^{*}$ phase of this material. While retaining power law 476 dependencies of the optical parameters $\left(\Delta n, \theta_{\text {App }}\right)$ on temperature with slightly different 477 exponents, the observed phenomena are well described by this model. The critical exponents 478 indicate that dimension of the system is greater than unity in agreement with the de-Vries nature 479 of the material. The soft mode relaxation strength from dielectric spectroscopy shows a critical 480 behavior when the $\mathrm{LC}$ system approaches $\mathrm{SmA}^{*}$ to $\mathrm{SmC}^{*}$ phase transition. The future development of the de-Vries model should include temperature dependencies of the minima and maxima of cone angles and the molecular biaxiality must be included in the model parameters. $\mathrm{X}$-ray scattering gives rise to sugar-loaf orientational distribution function but it does not exclude the observation of the diffused cone model for the electro-optical effects (birefringence and the tilt angle) as explained in the text. It would also appear that the presence of the two chiral centres in the molecule does not prevent this material from exhibiting the de Vries behaviour.

\section{ACKNOWLEDGEMENTS}

This work was supported by 13/US/I2866 from the Science Foundation of Ireland as part of the US-Ireland Research and Development Partnership program jointly administered with the United States National Science Foundation under grant number NSF-DMR-1410649 and by

491 the DFG (Grant TS 39/24-1). A. Kocot thanks National Science Centre Poland for grant 492 2011/03/B/ST3/03369. 


\section{Appendix A:}

\section{Synthetic Procedure}

495 All reagents were purchased from Sigma Aldrich, Fluorochem, Alfa Aesar, ABCR and used 496 without any further purification. Solvents were purchased from Sigma Aldrich, DMF was 497 purchased pre-dried, THF was dried using a sodium/benzophenone still under $\mathrm{N}_{2}$. All reactions 498 were generally carried out under argon using oven-dried glassware. TLC plates were performed 499 on Merck silica gel $60 \mathrm{~F}_{254}$ and were visualized using a $254 \mathrm{~nm}$ light source. Flash column 500 chromatography was performed on Fluorochem silica gel 60 (40-63 micron).

$501{ }^{1} \mathrm{H}$ and ${ }^{13} \mathrm{C}$ spectra were recorded at $25^{\circ} \mathrm{C}\left(\mathrm{CDCl}_{3}\right.$ as solvent and TMS as reference) using a 502 Bruker $400 \mathrm{MHz}$ Ultrashield (Avance 400). HRMS spectra were recorded using a Waters - TOF 503 Electrospray micromass LCT premier.

504 Procedures for each reaction are provided below.

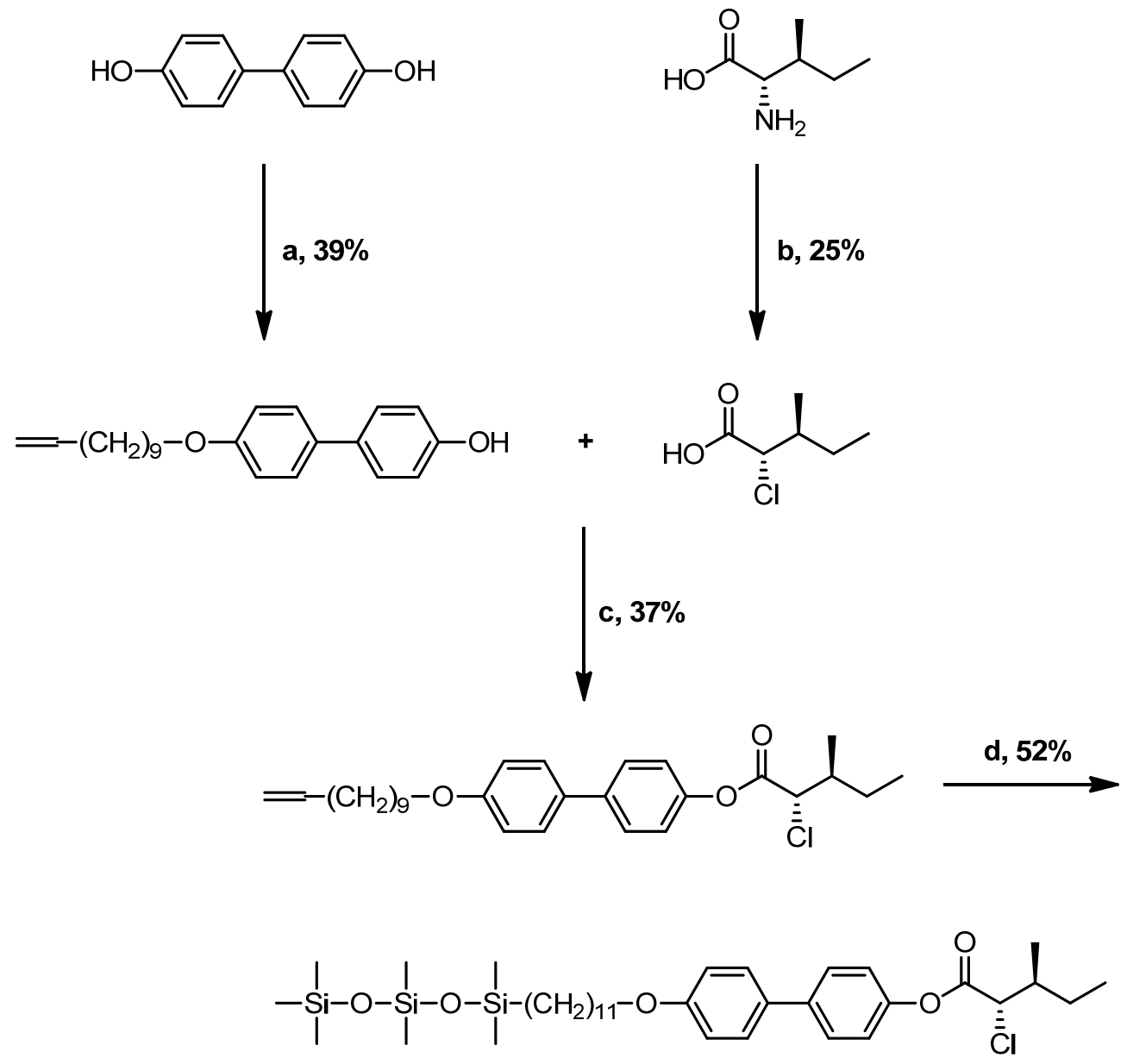
507 Fig. 12. Reagents and conditions: a) 11-bromo-1-undecene, $\mathrm{K}_{2} \mathrm{CO}_{3}$, DMF; b) $\mathrm{NaNO}_{2}, \mathrm{HCl}, \mathrm{H}_{2} \mathrm{O}$,
$508 \quad 0{ }^{\circ} \mathrm{C}$; c) DMAP, DCC, THF; d) 1,1,1,3,3,5,5-heptamethyltrisiloxane, Karstedt's catalyst, THF. 


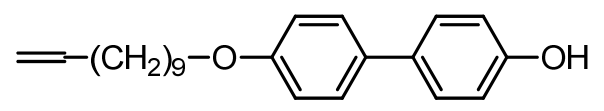

516 4,4'-dihydroxybiphenyl (5.00 g, $26.85 \mathrm{mmol}), 11$-bromo-1-undecene (6.26 g, $26.85 \mathrm{mmol})$ and 517 potassium carbonate $(3.72 \mathrm{~g}, 26.92 \mathrm{mmol})$ were dissolved in dry DMF $(25 \mathrm{~mL})$ under nitrogen 518 and stirred at room temperature overnight. Water $(25 \mathrm{~mL})$ was added, the solution was 519 neutralised with $\mathrm{HCl}(1 \mathrm{M})$ and the precipitate was filtered. The solid was dissolved in hot 520 ethanol and any insoluble particles were filtered. The suspension which formed is then filtered a second time to yield a white powder (3.40 g, $10.04 \mathrm{mmol}, 37 \%)$.

522
${ }^{1} \mathrm{H}$ NMR $\left(400 \mathrm{MHz}, \mathrm{CDCl}_{3}\right) \delta: 7.45(\mathrm{~d}, J=6.7,2 \mathrm{H}), 7.42(\mathrm{~d}, J=6.6,2 \mathrm{H}), 6.94(\mathrm{~d}, J=8.7,2 \mathrm{H})$, $6.88(\mathrm{~d}, J=8.6,2 \mathrm{H}), 5.82(\mathrm{~m}, 1 \mathrm{H}), 4.98(\mathrm{~m}, 2 \mathrm{H}), 4.72(\mathrm{~m}, 1 \mathrm{H}), 3.98(\mathrm{t}, J=6.6,2 \mathrm{H}), 2.04(\mathrm{~m}$, $2 \mathrm{H}), 1.78(\mathrm{~m}, 2 \mathrm{H}), 1.65-1.2(\mathrm{~m}, 12 \mathrm{H})$.

(2S,3S)-2-chloro-3-methylpentanoic acid (T2)<smiles>CCC(C)[C@H](Cl)C(=O)O</smiles>

FIG. 14, T2

A suspension of L-isoleucine $(5.00 \mathrm{~g}, 38.12 \mathrm{mmol})$ in $6 \mathrm{M} \mathrm{HCl}(40 \mathrm{~mL})$ was cooled to $0{ }^{\circ} \mathrm{C}$. A solution of sodium nitrite $(2.63 \mathrm{~g}, 38.12 \mathrm{mmol})$ in water $(15 \mathrm{~mL})$ was added drop-wise. Solution was stirred for 4 hours at $0{ }^{\circ} \mathrm{C}$ and 1 hour at room temperature. The compound was extracted with ethyl acetate and dried with magnesium sulphate. The solvent was evaporated and the oil distilled to give a light yellow oil (1.43 g, $9.50 \mathrm{mmol}, 25 \%)$.

${ }^{1} \mathrm{H}$ NMR (400 MHz, $\left.\mathrm{CDCl}_{3}\right) \delta: 9.28(\mathrm{~s}, 1 \mathrm{H}), 4.22(\mathrm{~d}, J=6.5,1 \mathrm{H}), 2.10(\mathrm{~m}, 1 \mathrm{H}), 1.65(\mathrm{~m}, 1 \mathrm{H})$, $1.34(\mathrm{~m}, 1 \mathrm{H}), 1.05(\mathrm{~d}, J=6.8,3 \mathrm{H}), 0.92(\mathrm{t}, \mathrm{J}=7.4,3 \mathrm{H})$.

(2S,3S)-4'-(undec-10-en-1-yloxy)-[1,1'-biphenyl]-4-yl 2-chloro-3-methylpentanoate T3 
538

539

540

541

542

543

544

545

546

547

548

549

550

551

552

553

554

555

556

557

558

559

560

561

562

563

564

565

566

567

568

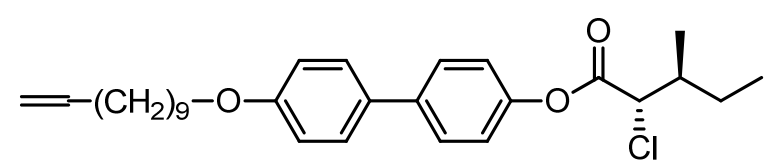

(FIG. 15, T3)

A solution of T1 (1.00 g, $2.95 \mathrm{mmol}), \mathrm{T} 2(0.44 \mathrm{~g}, 2.95 \mathrm{mmol})$, DMAP (0.04 g, $0.33 \mathrm{mmol})$ and N,N'- Dicyclohexylcarbodiimide $(0.61 \mathrm{~g}, 2.96 \mathrm{mmol})$ in dry THF $(30 \mathrm{~mL})$ were sealed under nitrogen and stirred overnight at room temperature. The precipitate was filtered and solvent evaporated. Crude was purified using column chromatography (ethyl acetate/hexane, 1:1, $\mathrm{R}_{\mathrm{f}}=$ 0.63). The compound was then dissolved in hot petroleum ether and any precipitate was filtered away to give a yellow wax $(0.52 \mathrm{~g}, 1.10 \mathrm{mmol}, 37 \%)$.

${ }^{1} \mathrm{H}$ NMR $\left(400 \mathrm{MHz}, \mathrm{CDCl}_{3}\right) \delta: 7.56(\mathrm{~d}, J=8.6,2 \mathrm{H}), 7.48(\mathrm{~d}, J=8.7,2 \mathrm{H}), 7.16(\mathrm{~d}, J=8.6,2 \mathrm{H})$, $6.96(\mathrm{~d}, J=8.7,2 \mathrm{H}), 5.82(\mathrm{~m}, 1 \mathrm{H}), 4.97(\mathrm{~m}, 2 \mathrm{H}), 4.40(\mathrm{~d}, J=7.1,1 \mathrm{H}), 3.99(\mathrm{t}, J=6.5,2 \mathrm{H}), 2.24$ $(\mathrm{m}, 1 \mathrm{H}), 2.05(\mathrm{~m}, 2 \mathrm{H}), 1.80(\mathrm{~m}, 3 \mathrm{H}), 1.70-1.16(\mathrm{~m}, 14 \mathrm{H}), 1.15(\mathrm{~d}, J=6.7,3 \mathrm{H}), 1.00(\mathrm{t}, J=7.4$, $3 \mathrm{H})$.

(2S,3S)-4'-((11-(1,1,3,3,5,5,5-heptamethyltrisiloxanyl)undecyl)oxy)-[1,1'-biphenyl]-4-yl

2chloro-3-methylpentanoate MSi3-MR11

(1)


$569{ }^{13} \mathrm{C}$ NMR (101 MHz, CDCl3) $\delta: 168.29$ (C), 159.12 (C), 149.49 (C), $139.42(\mathrm{C}), 132.72(\mathrm{C})$, $570128.33(\mathrm{CH}), 128.00(\mathrm{CH}), 121.58(\mathrm{CH}), 115.07(\mathrm{CH}), 68.36(\mathrm{CH} 2), 62.88(\mathrm{CH}), 39.31(\mathrm{CH})$, $57133.68(\mathrm{CH} 2), 29.87(\mathrm{CH} 2), 29.82(2 \mathrm{CH} 2), 29.64(\mathrm{CH} 2), 29.62(\mathrm{CH} 2), 29.52(\mathrm{CH} 2), 26.29$ 572 (CH2), $25.39(\mathrm{CH} 2), 23.45(\mathrm{CH} 2), 18.52(\mathrm{CH} 2), 16.22(\mathrm{CH} 3), 11.11(\mathrm{CH} 3), 2.04(3 \mathrm{CH} 3), 1.50$ 573 (2CH3), $0.43(2 \mathrm{CH} 3)$.

574 HRMS (EI): calcd for $\mathrm{C}_{36} \mathrm{H}_{61} \mathrm{ClO}_{5} \mathrm{Si}_{3} \mathrm{Na}\left[\mathrm{M}+\mathrm{Na}^{+}\right]$715.3413, found: 715.3438.

575

576

577

578

579

580

581

582

583

584

585

586

587

588

589

590

591

592

593

594 
596 [1] S. Kumar, Phys. Rev. A 23, 3207 (1981).

597 [2] C. R. Safinya, R. J. Birgeneau, J. D. Litster, and M. E. Neubert, Phys. Rev. Lett. 47, 668 $598 \quad$ (1981).

599 [3] J. P. Lagerwall and F. Giesselmann, Chem. Phys. Chem. 7, 20 (2006).

600 [4] T. P. Rieker, N. A. Clark, G. S. Smith, D. S. Parmar, E. B. Sirota, and C. R. Safinya, 601 Phys. Rev. Lett. 59, 2658 (1987).

602 [5] N. A. Clark and S. T. Lagerwall, Appl. Phys. Lett. 36, 899 (1980).

603 [6] S. Diele, P. Brand, and H. Sackmann, Mol. Cryst. Liq. Cryst. 16, 105 (1972).

604 [7] A. de Vries, Abstracts Book of the 5th International Liquid Crystal Conference, 150, 605 Stockholm, (1974).

606 [8] A. de Vries, Mol. Cryst. Liq. Cryst. 41, 27 (1977).

607 [9] A. de Vries, A. Ekachai, and N. Spielberg, Mol. Cryst. Liq. Cryst. Lett. 49, 143 (1979).

608 [10] Y. Takanishi, Y. Ouchi, H. Takezoe, A. Fukuda, A. Mochizuki, M. Nakatsuka, Jpn. J. Appl. 609 Phys. 29, L984 (1990).

610 [11] M. D. Radcliffe, M. L. Brostrom, K. A. Epstein, A. G. Rappaport, B. N. Thomas, R. Shao, 611 and N. A. Clark, Liq. Cryst. 26, 789 (1999).

612 [12]. H. G. Yoon, D. M. Agra-Kooijman, K. Ayub, R. P. Lemieux, and S. Kumar, Phys. Rev. 613 Lett. 106, 087801 (2011).

614 [13] D. M. Agra-Kooijman, H. G. Yoon, S. Dey, and S. Kumar, Phys. Rev. E 89, 032506 (2014).

615 [14] K. Merkel, A. Kocot, J. K. Vij, P. J. Stevenson, A. Panov, and D. Rodriguez, Appl. Phys. 616 Lett. 108, 243301 (2016).

617 [15] N. Hayashi, T. Kato, A. Fukuda, J. K. Vij, Yu. P. Panarin, J. Naciri, R. Shashidhar, S.

618 Kawada and Sh. Kondoh, Phys. Rev. E 71, 041705 (2005).

619 [16] Ch. Bahr and G. Heppke, Phys. Rev. A 41, 4335 (1990).

620 [17] U. Manna, J. -K. Song, Yu. P. Panarin, A. Fukuda and J. K. Vij, Phys. Rev. E 77, 041707 621 (2008).

622 [18] O. E. Panarina, Yu. P. Panarin, J. K. Vij, M. S. Spector, and R. Shashidhar, Phys. Rev. E 67, $623051709(2003)$.

624 [19] O. E. Panarina, Yu. P. Panarin, F. Antonelli, M. Reihmann, and G. Galli, J. Mater. Chem. $62516,842(2006)$.

626 [20] M. S. Spector, P. A. Heiney, J. Naciri, B. T. Weslowski, D. B. Holt and R. Shashidhar, 627 Phys. Rev. E 61, 1579-1584 (2000). 
628 [21] Y. Shen, L. Wang, R. Shao, T. Gong, C. Zhu, H. Yang, J. E. Maclennan, D. M. Walba, and 629 N. A. Clark, Phys. Rev. E 88, 062504 (2013).

630 [22] J. P. F. Lagerwall, F. Giesselmann and M. D. Radcliffe, Phys. Rev. E 66, 031703 (2002).

631 [23] G. Galli, M. Reihmann, A. Crudeli, E. Chiellini, Yu. P. Panarin, J. K. Vij, C. Blanc, V. 632 Lorman, and N. Olsson, Mol. Cryst. Liq. Cryst. 439, 2111 (2005).

633 [24] M. J. Frisch et al.; Gaussian 09, Revision E.01 Gaussian, Inc., Wallingford CT, (2009).

634 [25] A. Mchisuki, and S. Kobayashi, Mol. Cryst. Liq. Cryst. 243, 77 (1994).

635 [26] A. P. Hammersley, S. O. Svensson, M. Hanfland, A. N. Fitch, and D. Hausermann,

636 High Pressure Research 14, 235. 1996

637 [27] V. P. Panov, J.K. Vij, Yu. P. Panarin, C. Blanc, V. Lorman, J. W. Goodby, Phys. Rev. E 75, 638042701 (2007).

639 [28] K. L. Sandhya, Yu. P. Panarin, V. P. Panov, J. K. Vij and R. Dabrowski, Eur. Phys. J. E 27, $640397(2008)$.

641 [29] K. Saunders, D. Hernandez, S. Pearson, and J. Toner, Phys. Rev. Lett. 98, 197801 (2007).

642 [30] B. Park, S. -S. Seomun, M. Nakata, M. Takahashi, Jpn. J. Appl. Phys. 38, 1474-1481 643 (1999).

644 [31] S. Garoff and R. B. Meyer, Phys. Rev. Lett. 38, 848 (1977); Phys. Rev. A 19, 338 (1979).

645 [32] A. Fukuda, Proceedings of the 15th International Display Research Conference of the SID 646 (Society for Information Display, San Jose, California, 1995), p. 61; S. Inui, N. Iimura, T.

647 Suzuki, H. Iwane, K. Miyachi, Y. Takanishi, and A. Fukuda, J. Mater. Chem. 6, 671 (1996).

648 [33] J. V. Selinger, P. J. Collings, and R. Shashidhar, Phys. Rev. E 64, 061705 (2001).

649 [34] N. A. Clark, T. Bellini, R. Shao, D. Coleman, S. Bardon, D. R. Link, J. E. Maclennan, X.

650 Chen, M. D. Wand, D. M. Walba, P. Rudquist, and S. T. Lagerwall, Appl. Phys. Lett. 80, $6514097(2002)$.

652 [35] P. J. Collings, B. R. Ratna, and R. Shashidhar, Phys. Rev. E 67, 021705 (2003).

653 [36] Z. V. Kost-Smith, P. D. Beale, N. A. Clark, and M. A. Glaser, Phys. Rev. E 87, 050502(R) 654 (2013).

655 [37] P. G. de Gennes and J. Prost, The Physics of Liquid Crystals, 2nd ed. (Clarendon Press, 656 Oxford, 1993), Sec. 10.2.1.

657 [38] P. Davidson, D. Petermann, and A. M. Levelut, J. Phys. II 5, 113 (1995).

658 [39] V. M. Vaksman and Yu. P. Panarin, Molecular Materials, 1, 147 (1992); V. Panov, J. K.

659 Vij, and N. M. Shtykov, Liquid Crystals, 28, 615 (2001).

660 [40] S. Havriliak (Jr.) and S. Negami, Polymer, 8, 161 (1967).

661 [41] O. E. Kalinovskaya and J. K. Vij, J. Chem. Phys. 111, 10979 (1999). 
662 [42] Yu. P. Panarin, H. Xu, S. T. Mac Lughadha, and J. K. Vij, Jpn. J. Applied Phys. (Part 1), 33, $6632648(1994)$.

664 [43] H. Xu, J. K. Vij, A. Rappaport and N. A. Clark, Phys. Rev. Lett. 79, 249 (1997).

665 [44] A. Kocot, R. Wrzalik, J. K. Vij, M. Brehmer and R. Zentel, Phys. Rev B 50, 16346 (1994). 